\title{
Effect of Cafeteria Diet Feeding on Soleus Intramyocellular Lipid of Wistar Rats
}

\author{
Cristina Cabot ${ }^{\mathrm{a}, \mathrm{b}}$, Karl Pouillota ${ }^{\mathrm{a}}$, Stéphanie Roy ${ }^{\mathrm{a}}$, Mar Romero ${ }^{\mathrm{a}, \mathrm{b}}$, Ruth Vila \\ Mar Grasa ${ }^{\mathrm{a}, \mathrm{b}, \mathrm{c}}$, Montserrat Esteve ${ }^{\mathrm{a}, \mathrm{b}, \mathrm{c}}$, José A. Fernández-López ${ }^{\mathrm{a}, \mathrm{b}, \mathrm{c}}$, \\ Marià Alemany ${ }^{\mathrm{a}, \mathrm{b}, \mathrm{c}}$, Xavier Remesar ${ }^{\mathrm{a}, \mathrm{b}, \mathrm{c}, \mathrm{d}}$
}

\begin{abstract}
Background: The presence of lipid besides muscle fibres facilitates the energy supply for exercise, but it is also indicative of insulin resistance in the untrained. Muscle lipid is associated with increased dietary energy: hyperlipidic diets induce an increase in intramyocellular lipid deposition in skeletal muscle.
\end{abstract}

Methods: In the present study we analyzed the changes in soleus (a red-fibre muscle) intracellular muscle content under a hyperlipidic (cafeteria) diet in Wistar rats. We also analyzed in parallel the mitochondrial content a relative index of energy output capability.

Results: Cafeteria diet-fed rats contained more lipid and mitochondria per unit of muscle section area than controls.

Conclusions: The correlation found in the increases of muscle lipid and mitochondria hit at this increase as an adaptation of muscle to oxidize excess energy substrates under conditions of excess energy availability, probably contributing to adaptive thermogenesis.

Keywords: Cafeteria diet; Intramyocellular lipid; Dietary energy; Muscle lipid; Mitochondria; Soleus muscle

\footnotetext{
Manuscript accepted for publication February 3, 2012

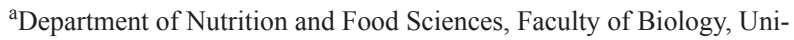
versity of Barcelona, Spain

${ }^{b}$ CIBER Physiopathology of Obesity and Nutrition, Institute of Health Carlos III, Spain

${ }^{\mathrm{c}}$ Institute of Biomedicine (IBUB), University of Barcelona, Spain

${ }^{\mathrm{d}}$ Correspondig autor: Xavier Remesar, Department of Nutrition and

Food Sciences, Faculty of Biology, University of Barcelona, Av.

Diagonal 643, 08028 Barcelona, Spain. Email: xremesar@ub.edu

doi:10.4021/jem63w
}

\section{Introduction}

Muscle accounts for about $40 \%$ of body weight, both in rats [1] and humans [2], thus constituting the largest organ/tissue of normal weight individuals. Muscle contains both structural lipids (mainly membrane phospholipid and cholesterol), and reserve-related lipids (mainly triacylglycerols). The latter include two different compartments: intramyocellular lipid (IMCL) and white adipose tissue cells. Muscle adipose tissue is often interspersed between muscle bundles and in contact with its surface and vessels [3].

Muscle reserve lipid supplies energy to sustain the muscle needs, especially during endurance exercise [4], a role largely sustained by IMCL. The content of IMCL (and mitochondria) in white-fibre glycolytic muscle is lower than in red-fibre oxidative muscle; since the main energy supply comes from glycolysis in white- and fatty acids in red-muscle fibres. The amount of lipid present in muscle is a critical factor for the duration of exercise endurance activity because it supplies a large part of the energy used in red-fibre muscles [5].

Hyperenergetic diets, i.e. hyperlipidic diets, tend to overcome the ability of the ponderostat system to maintain the mass of body energy reserves [6] when administered for long periods of time. This helps increase muscle fat deposition in both compartments IMCL and adipose tissue cells. Cafeteria diet, a self-selected highly palatable diet [7], is hyperenergetic because it contains a high proportion of lipid, selected in excess by the rats, whilst the proportions of protein and carbohydrate ingested are better regulated and comparable to those of controls fed rat chow pellets [8]. Rats with access to a cafeteria diet accumulate a high amount of body fat [9], primarily found in large white adipose tissue masses, but also in disperse or small anatomically distinct masses [10]. In general, hyperlipidic diets increase the storage of fat in other organs such as liver and muscle [11], increasing IMCL [12].

The actual meaning of increased IMCL by hyperlipidic diets is unclear, since excess lipid may hamper the normal operation of muscle, as found in some cardiomyopathies [13] in which heart muscle function is affected by deposits 
of very long-chain fatty acids in triacylglycerols [14]. It may be speculated that excess muscle lipid accumulation is a consequence of high fatty acids availability, and their use as fuel for muscle contraction in insulin resistance [15]. However, under standard conditions blood-carried glucose, and lipoprotein triacylglycerols (supplying fatty acids in addition to those carried bound to albumin) seem enough to maintain the muscle in full operative conditions.

In the present study we intended to analyze the IMCL content of the soleus, a red-fibre muscle, and its modulation by a limited exposure to a hyperlipidic cafeteria diet. We limited the extension of dietary lipid exposure to obtain a sizeable overweight, but not full-blown obesity [16] characterized by massive metabolic derangement. This particular muscle was selected because its isolation allows for a "clean" extraction, free of perimuscular and interspersed adipose tissue.

\section{Materials and Methods}

\section{Animals and diets}

Wistar 60-day old male rats (Harlan-Interfauna, Sant Feliu de Codines, Spain) were used. They were maintained under standard conditions $\left(21-22{ }^{\circ} \mathrm{C}, 50-60 \%\right.$ relative humidity, and $12 \mathrm{~h} \mathrm{light/dark} \mathrm{cycle)} \mathrm{in} \mathrm{two-rat} \mathrm{cages.} \mathrm{A} \mathrm{6-rat} \mathrm{control}$ group was maintained under these conditions, and fed $a d$ libitum with standard rat chow (maintenance type, Panlab, Barcelona, Spain) for 30 days. A second group was given a simplified cafeteria diet [17] in addition to the standard chow for 30 days, when the cafeteria-fed rats were already overweight [18].

All animal handling procedures were carried out following the guidelines established by the EU, and the Spanish and Catalan Governments. The Ethics Committee of the University of Barcelona approved the experimental setup and procedures.

\section{Muscle dissection and lipid analysis}

At the end of the 30-day diet exposure period, the rats were killed by decapitation. The left leg soleus muscle was immediately exposed and bathed (first in situ and later $24 \mathrm{~h}$ in an container placed in ice, until processed) with chilled fixing solution $(25 \mathrm{~g} / \mathrm{L}$ gluraraldehyde and $20 \mathrm{~g} / \mathrm{L}$ paraformaldehyde in $100 \mathrm{mM}$ phosphate buffer $\mathrm{pH}$ 7.2) [19] during the process of dissection and later storage. The right leg muscle was dissected and weighed, then frozen in liquid $\mathrm{N}$, and kept at $-80{ }^{\circ} \mathrm{C}$. Right-leg muscles were homogenized in trichloromethane-methanol $(2: 1 \mathrm{v} / \mathrm{v})$ in the cold using a Potter-Elvejhem type all-glass homogenizer. The clear organic supernatant was used for the gravimetric estimation of total sample lipid [20].
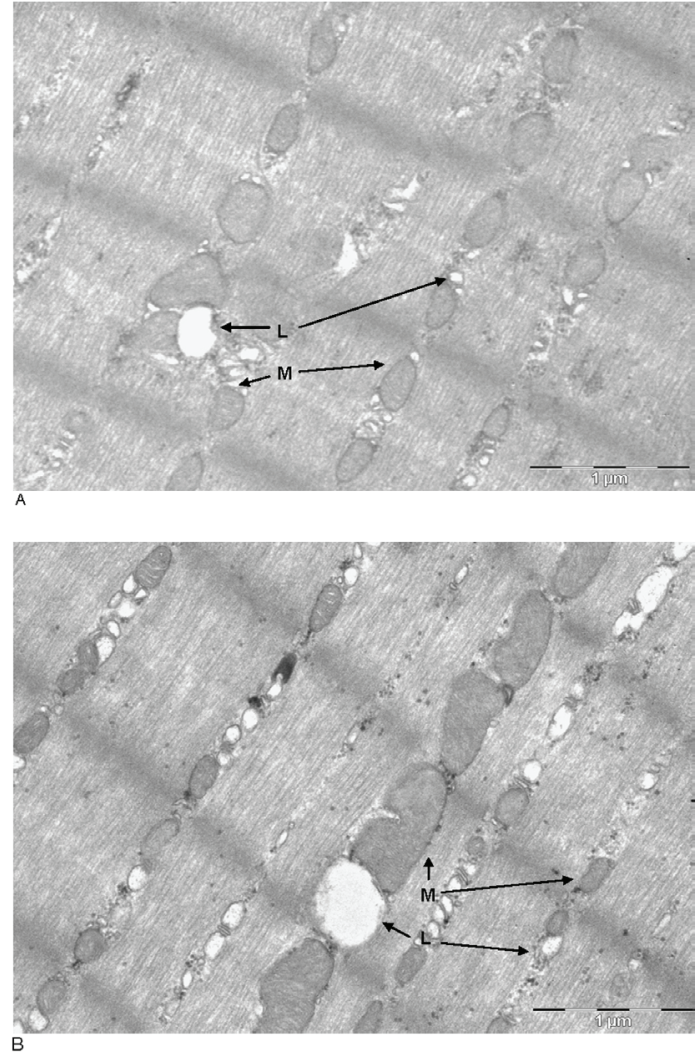

Figure 1. Transmission electronic microscope photographs of soleus muscles of male Wistar rats fed control (A, top) or cafeteria diet $\left(\mathrm{B}\right.$, bottom). The cuts were stained with $\mathrm{OsO}_{4}$. $\mathrm{M}$ : mitochondria; L: lipid droplet. Magnification: the bar represents $1000 \mathrm{~nm}$.

\section{Microphotographic analysis of intramyocellular lipid}

The fixed tissues were treated with $10 \mathrm{~g} / \mathrm{L}$ osmium tetroxide [21] for 1 hour. Then the muscles were dehydrated with acetone and included in an epoxy resin (Eponate 12, Ted Pella Inc., Redding CA, USA). The hardened pieces were cut longitudinally in a microtome (Leica Ultracut, Wetzler, Germany) obtaining $60 \mathrm{~nm}$ thick sections. The cuts were observed at 30,000 $\times$ magnification using a JEOL JEM-1010 (Akishima, Japan) transmission electronic microscope. We obtained 45 microphotographs from each sample following an aleatory protocol for the selection of the cuts and fields. The resulting images were processed with the AnalySIS (Soft Imaging Systems, Munster, Germany) program after manual delimitation of both lipid vacuoles and mitochondria.

Statistical analyses were carried out using the paired Student's $t$ test.

\section{Results}

Total lipid content in soleus did not shown differences be- 
Table 1. Lipid and Mitochondria Content of Soleus Muscle of Control and Cafeteria Diet-Fed Male Rats

\begin{tabular}{lllll}
\hline Parameter & units & 30 day-control diet & 30 day-cafeteria diet & P \\
\hline Mean lipid droplet area & $\mu \mathrm{m}^{2}$ & $0.014 \pm 0.001$ & $0.016 \pm 0.001$ & NS \\
Number of lipid droplets per field & & $19.1 \pm 3.71$ & $23.1 \pm 5.11$ & NS \\
Lipid droplet area per field & $\mu \mathrm{m}^{2}$ & $0.171 \pm 0.083$ & $0.244 \pm 0.012$ & $<0.001$ \\
& $\%$ of FSA & $1.24 \pm 0.06$ & $1.77 \pm 0.09$ & NS \\
Mean mitochondria area & $\mu \mathrm{m}^{2}$ & $0.057 \pm 0.003$ & $0.064 \pm 0.003$ & $\mathrm{NS}$ \\
Number of mitochondria per field & & $10.3 \pm 1.91$ & $11.1 \pm 1.01$ & $<0.001$ \\
& $\mu \mathrm{m}^{2}$ & $0.530 \pm 0.018$ & $0.682 \pm 0.029$ & $<0.001$ \\
\hline
\end{tabular}

$\%$ of FSA $=$ percentage of the observed field $=$ s surface area $\left(13.82 \mu \mathrm{m}^{2}\right)$.

tween groups $(3.77 \pm 0.28 \mathrm{mg}$ in control rats and $4.59 \pm 0.39$ $\mathrm{mg}$ in cafeteria-fed rats. Figure 1 shows representative microphotographs of the soleus muscles of Wistar male rats fed control or cafeteria diets. The number/size of lipid droplets and mitochondria were more abundant in the cafeteria dietfed animals. The quantitative data are summarized in Table 1 , where the number of lipid droplets and their size (as well as those of mitochondria) are presented referred to the standardized microphotograph field. In spite of the means being higher for both series of parameters in cafeteria than in control rats, the differences were not significant. However, when comparing the combined lipid or mitochondrial areas per field between both dietary groups, the differences became significant, i.e. cafeteria diet-fed rats contained more lipid and mitochondria per unit of muscle section area than controls. The correlation between the numbers of lipid droplets per field versus the number of mitochondria per field resulted in $\mathrm{P}$ values of 0.144 (not significant) for controls, 0.021 for cafeteria and 0.008 for all animals (control + cafeteria) combined. This shows that the counts for mitochondria and lipid droplets are correlated, irrespective of diet, since the sizes of both mitochondria and lipid droplets were similar in both dietary groups (albeit slightly larger, but not significantly, in cafeteria muscles) we can safely assume that the number of lipid droplets and mitochondria in the muscle were correlated, increasing in parallel with cafeteria feeding, since the total amount of lipid in the (right leg) muscles of cafeteriafed rats were higher than in controls.

\section{Discussion}

The increase in lipid content of the whole body and indi- vidual tissues under a hyperlipidic diet has been repeatedly described in the literature [22], comprising increases in total muscle lipid [23], and even in IMCL [24]. This increase is currently attributed to an excessive availability of lipid, and the need to store it somehow/somewhere, both as reserve and as a way to minimize, in the short term, its potentially lipotoxic effects. However, muscle lipid has a well-defined function, that of supplying red-fiber muscles with a reliable source of fuel for sustained activity; thus, an excess of lipid deposition may induce a loss of efficiency by hampering muscle function [25]. It may be construed that lipid accumulation in muscle intracellular space may result in the equivalent of hepatic steatosis, in that excess lipid storage impairs liver function [26]. In addition, the special fibrous nature of muscle leaves little space for lipid storage, which in some way must "compete" for space with other cell organelles such as mitochondria, endoplasmic reticulum, sarcolemma sacs and glycogen granules.

Lipid accumulation in soleus muscle is detectable and statistically significant under conditions of excess lipid availability and enhanced storage elsewhere; however not to the extent observed in other tissues such as liver or, specially, adipose tissue [27]. The parallel rise in the number of mitochondria marks another important difference, unparalleled in other lipid-storing tissues, since its function is clearly oxidative and counterpoised to the storage of "excess" energy. An increased number of (normal-size) mitochondria hints to an increased capability of ATP synthesis for muscle operation.

However, both control and cafeteria diet-fed rats were kept in limited spaces (cages) in which no sustained exercise was practically possible (neither observed), which does not justify any increase in power output (ATP) capability that 
a higher number of mitochondria represent [28]. Continued exercise increases muscle mass, mitochondria and power output; but here we observe this potential increase in power output without the previous stimulus of exercise. It may be, thus, postulated, that the higher accumulation of lipid in muscle triggers mitochondriogenesis, but the ultimate reason for this increase remains obscure.

Thermogenesis is the main mechanism for adjusting energy availability and energy needs in mammals (in higher proportion in the smaller ones) by converting excess nutrients into heat. This role is usually carried out, at least in rodents, mainly by brown adipose tissue [29], which uncoupling mechanism is nowadays widely known [30]. However, brown adipose tissue thermogenesis does not explain a significant part of whole body adaptive thermogenesis, including the possible role of liver [31], overall inefficiency elicited by thyroid hormones [32], and muscle activity [33]. A higher energy wasting by muscle has been attributed to increased expenditure in maintaining muscle tone [34], but no "chemical" mechanisms have been advanced to explain the role of muscle in wasting energy in thermogenic processes. The usual way of heating muscle up to fully functional temperature remains shivering thermogenesis [35], directly related to cold exposure.

Recent studies have shown that muscle thermogenesis may represent a significant proportion of total body heat production, especially because of its large proportion versus body weight [36]. Analysis of muscle mitochondria operation in obese rodents has shown an increase in inefficiency [37] which may result in permanent metabolic damages in severe obesity [38].

The role of muscle as wasting energy organ for excess available energy has not been sufficiently explored, probably because of its dispersion, different structure, fibre composition and interspersed conjunctive and adipose tissues. In addition a small contribution of mitochondrial inefficiency may account for a significant proportion of thermogenesis in small animals [39] because of their total muscle large weight, an effect probably magnified in humans because of less significant contributions of brown adipose tissue [40].

In this context, the parallel increase in muscle lipid and mitochondria makes sense, and may help explain the oxidation of excess energy in muscle to produce heat. So far, we don't know precisely the mechanism of energy wasting [41], but the machinery is in place, responds to a clear metabolic challenge and may explain the postulated implication of muscle in "chemical" thermogenesis.

\section{Grant Support}

SAF2009 11739 of the Plan Nacional de Biomedicina and AGL2010-19740 of the Plan Nacional Ciencia y Tecnología de Alimentos of the Government of Spain.

\section{References}

1. Arola L, Herrera E, Alemany M. A method for the estimation of striated muscle mass in small laboratory animals. Rev Esp Fisiol. 1979;35(2):215-218.

2. Wang ZM, Pierson RN, Jr., Heymsfield SB. The fivelevel model: a new approach to organizing body-composition research. Am J Clin Nutr. 1992;56(1):19-28.

3. Vettor R, Milan G, Franzin C, Sanna M, De Coppi P, Rizzuto R, Federspil G. The origin of intermuscular adipose tissue and its pathophysiological implications. Am J Physiol Endocrinol Metab. 2009;297(5):E987-998.

4. Krssak M, Petersen KF, Bergeron R, Price T, Laurent D, Rothman DL, Roden M, et al. Intramuscular glycogen and intramyocellular lipid utilization during prolonged exercise and recovery in man: a $13 \mathrm{C}$ and $1 \mathrm{H}$ nuclear magnetic resonance spectroscopy study. J Clin Endocrinol Metab. 2000;85(2):748-754.

5. Tarnopolsky MA, Rennie CD, Robertshaw HA, FedakTarnopolsky SN, Devries MC, Hamadeh MJ. Influence of endurance exercise training and sex on intramyocellular lipid and mitochondrial ultrastructure, substrate use, and mitochondrial enzyme activity. Am J Physiol Regul Integr Comp Physiol. 2007;292(3):R1271-1278.

6. Akiyama T, Tachibana I, Shirohara H, Watanabe N, Otsuki M. High-fat hypercaloric diet induces obesity, glucose intolerance and hyperlipidemia in normal adult male Wistar rat. Diabetes Res Clin Pract. 1996;31(13):27-35.

7. Castella J, Alemany M. Thermogenic effects of a "cafeteria" diet on the rat during its reproductive cycle. Comp Biochem Physiol A Comp Physiol. 1986;85(2):203-206.

8. Rothwell NJ, Stock MJ. The cafeteria diet as a tool for studies of thermogenesis. J Nutr. 1988;118(8):925-928.

9. Sclafani A, Springer D. Dietary obesity in adult rats: similarities to hypothalamic and human obesity syndromes. Physiol Behav. 1976;17(3):461-471.

10. Naim M, Brand JG, Kare MR, Carpenter RG. Energy intake, weight gain and fat deposition in rats fed flavored, nutritionally controlled diets in a multichoice ("cafeteria") design. J Nutr. 1985;115(11):1447-1458.

11. Korach-Andre M, Gao J, Gounarides JS, Deacon R, Islam A, Laurent D. Relationship between visceral adiposity and intramyocellular lipid content in two rat models of insulin resistance. Am J Physiol Endocrinol Metab. 2005;288(1):E106-116.

12. de Meijer VE, Le HD, Meisel JA, Akhavan Sharif MR, Pan A, Nose V, Puder M. Dietary fat intake promotes the development of hepatic steatosis independently from excess caloric consumption in a murine model. Metabolism. 2010;59(8):1092-1105.

13. Sharma S, Adrogue JV, Golfman L, Uray I, Lemm J, Youker K, Noon GP, et al. Intramyocardial lipid accumulation in the failing human heart resembles the lipo- 
toxic rat heart. FASEB J. 2004;18(14):1692-1700.

14. Corcoran MP, Lamon-Fava S, Fielding RA. Skeletal muscle lipid deposition and insulin resistance: effect of dietary fatty acids and exercise. Am J Clin Nutr. 2007;85(3):662-677.

15. Perseghin G, Scifo P, Danna M, Battezzati A, Benedini S, Meneghini E, Del Maschio A, et al. Normal insulin sensitivity and IMCL content in overweight humans are associated with higher fasting lipid oxidation. Am J Physiol Endocrinol Metab. 2002;283(3):E556-564.

16. Prats E, Monfar M, Castella J, Iglesias R, Alemany M. Energy intake of rats fed a cafeteria diet. Physiol Behav. 1989;45(2):263-272.

17. Esteve M, Rafecas I, Remesar X, Alemany M. Nitrogen balances of lean and obese Zucker rats subjected to a cafeteria diet. Int J Obes Relat Metab Disord. 1992;16(4):237-244.

18. Ferrer-Lorente R, Cabot C, Fernandez-Lopez JA, Remesar X, Alemany M. Effects of oleoyl-estrone with dexfenfluramine, sibutramine or phentermine on overweight rats. Eur J Pharmacol. 2005;513(3):243-248.

19. Sabatini DD, Bensch K, Barrnett RJ. Cytochemistry and electron microscopy. The preservation of cellular ultrastructure and enzymatic activity by aldehyde fixation. J Cell Biol. 1963;17:19-58.

20. Bruns RR, Palade GE. Studies on blood capillaries. I. General organization of blood capillaries in muscle. J Cell Biol. 1968;37(2):244-276.

21. Folch J, Lees M, Sloane Stanley GH. A simple method for the isolation and purification of total lipides from animal tissues. J Biol Chem. 1957;226(1):497-509.

22. Coenen KR, Gruen ML, Chait A, Hasty AH. Diet-induced increases in adiposity, but not plasma lipids, promote macrophage infiltration into white adipose tissue. Diabetes. 2007;56(3):564-573.

23. Bachmann OP, Dahl DB, Brechtel K, Machann J, Haap M, Maier T, Loviscach M, et al. Effects of intravenous and dietary lipid challenge on intramyocellular lipid content and the relation with insulin sensitivity in humans. Diabetes. 2001;50(11):2579-2584.

24. St-Onge MP, Newcomer BR, Buchthal S, Aban I, Allison DB, Bosarge A, Gower B. Intramyocellular lipid content is lower with a low-fat diet than with high-fat diets, but that may not be relevant for health. Am J Clin Nutr. 2007;86(5):1316-1322.

25. Schrauwen-Hinderling VB, Hesselink MK, Schrauwen $P$, Kooi ME. Intramyocellular lipid content in human skeletal muscle. Obesity (Silver Spring). 2006;14(3):357367.

26. Unger RH. The physiology of cellular liporegulation. Annu Rev Physiol. 2003;65:333-347.

27. Hegarty BD, Cooney GJ, Kraegen EW, Furler SM. Increased efficiency of fatty acid uptake contributes to lipid accumulation in skeletal muscle of high fat-fed insulin-resistant rats. Diabetes. 2002;51(5):1477-1484.

28. Gollnick PD, King DW. Effect of exercise and training on mitochondria of rat skeletal muscle. Am J Physiol. 1969;216(6):1502-1509.

29. Rothwell NJ, Stock MJ. A role for brown adipose tissue in diet-induced thermogenesis. Nature. 1979;281(5726):31-35.

30. Samec S, Seydoux J, Dulloo AG. Role of UCP homologues in skeletal muscles and brown adipose tissue: mediators of thermogenesis or regulators of lipids as fuel substrate? FASEB J. 1998;12(9):715-724.

31. Ma SW, Nadeau BE, Foster DO. Evidence for liver as the major site of the diet-induced thermogenesis of rats fed a "cafeteria" diet. Can J Physiol Pharmacol. 1987;65(8):1802-1804.

32. Silva JE. Thyroid hormone control of thermogenesis and energy balance. Thyroid. 1995;5(6):481-492.

33. Astrup A, Bulow J, Christensen NJ, Madsen J, Quaade F. Facultative thermogenesis induced by carbohydrate: a skeletal muscle component mediated by epinephrine. Am J Physiol. 1986;250(2 Pt 1):E226-229.

34. Morrison SF, Nakamura K, Madden CJ. Central control of thermogenesis in mammals. Exp Physiol. 2008;93(7):773-797.

35. Banet M, Hensel H, Liebermann H. The central control of shivering and non-shivering thermogenesis in the rat. J Physiol. 1978;283:569-584.

36. Powell-Jones K, Saunders WS, St Onge RD, Thornill JA. Skeletal muscle thermogenesis: its role in the hyperthermia of conscious rats given morphine or beta-endorphin. J Pharmacol Exp Ther. 1987;243(1):322-332.

37. Ramsey JJ, Johnson DE, Hossner KL, Johnson KA. Metabolic rate, organ mass, and mitochondrial proton leak variations in lean and obese rats. Comp Biochem Physiol B Biochem Mol Biol. 1996;113(3):461-466.

38. Bakkman L, Fernstrom M, Loogna P, Rooyackers O, Brandt L, Lagerros YT. Reduced respiratory capacity in muscle mitochondria of obese subjects. Obes Facts. 2010;3(6):371-375.

39. Cypess AM, Lehman S, Williams G, Tal I, Rodman D, Goldfine AB, Kuo FC, et al. Identification and importance of brown adipose tissue in adult humans. N Engl J Med. 2009;360(15):1509-1517.

40. van den Berg SA, van Marken Lichtenbelt W, Willems van Dijk K, Schrauwen P. Skeletal muscle mitochondrial uncoupling, adaptive thermogenesis and energy expenditure. Curr Opin Clin Nutr Metab Care. 2011;14(3):243-249.

41. Stewart MA, Franks-Skiba K, Chen S, Cooke R. Myosin ATP turnover rate is a mechanism involved in thermogenesis in resting skeletal muscle fibers. Proc Natl Acad Sci U S A. 2010;107(1):430-435. 